\title{
Career Self-Efficacy as a Mediator Between Emotional Intelligence and Employment Planning Among US College Students
}

\author{
Magnus A. Gray \\ University of Arkansas at Monticello \\ Minsung Kim \\ Defence Language Institute Foreign Language Center \\ Seungyeon Lee \\ University of Arkansas at Monticello
}

\begin{abstract}
This study examines the dynamics of personality traits that tend to interfere with occupational decisions in young adults. Three multiple regression analyses were conducted to predict career decision self-efficacy (CDSE), e.g., planning and indecision with the Big 5 personality measures. We hypothesized that emotional intelligence (EI) and other personality traits affect employment conflicts (Study 1) and that CDSE mediates EI and planning difficulty (Study 2). Conscientiousness and openness significantly predicted CDSE, $\mathrm{F}(5,128)$ $=15.64, \mathrm{p}<.001, \mathrm{R}^{2}=.38$, while neuroticism was statistically significant in predicting the career student planning scale $($ CSPS $), F(5,128)=3.94, p$ $<.01, \mathrm{R}^{2}=.13$, and was significant for personality variables: a negative correlation was found between EI and career indecision $(r=-.25$, at $\mathrm{p}<.01)$. This demonstrates that the positive effect of CDSE mediates EI to career indecision, showing that conscientiousness predicted participants' indecision $(\beta=-.17, \mathrm{p}<.05)$.
\end{abstract}

Keywords: Big 5 personality traits, career indecision, career student planning scale (CSPS), emotional intelligence (EI)
Social distancing rules caused by the COVID-19 pandemic lockdowns created feelings of isolation, leading to mental health issues, which affected self-discipline, orderliness, procrastination, work performance, CDSE, and occupational indecision (Ahorsu et al., 2020; Gray et al., 2020; Tomaszek \& Muckacka-Cymerman, 2020). Gray, Kim, and Lee (2021) posit that the majority of college students and young adults were coping with mental health problems, which would ostensibly affect academic performance and vocational planning. Tomaszek and Muckacka-Cymerman (2020) found that young adults' mental health and career decisions were priorities across institutions. These researchers created other parameters about how resilience and positive well-being remain challenged due to the long-lasting impact of the recent pandemic.

\section{Employment decisions are} clearly a source of stress among college students, considering that nothing is predictable with public health emergencies and its mortality statistics (Ahorsu et al., 2020; Campagna \& Curtis, 2007; Gray et al., 2020; Mahmud, Talukder, \& Rahman, 2020; Mojgan, Kadir, \& Soheil, 2011). Ahorsu et al. (2020) suggest that young adults were anxious about their professional lives, particularly when factored into the worldwide pandemic anxiety. Other variables to consider are emotional intelligence (EI), career decision self-efficacy (CDSE), planning, and personality traits. Previous literature shows that EI is positively correlated with future work and that CDSE mediates these variables (Fabio, Palazzechi, Levin, \& Gati, 2015; Gati, Krausz, \& Osipow, 1996; MacCann et al., 2020). Given the uncertainty of any pandemic, little has been investigated about the causal issues among these variables.

Previous research on mental health issues and traumatic events indicates how a pandemic can easily lead to mental health and behavioral issues (Mahmud, Talukder, \& Rahman, 2020; Spurk \& Straub, 2020; Tomaszek \& Muchacka-Cymerman, 2020); However, there is little research on these variables conducted during an actual pandemic. A number of studies indicate that mental health issues affect young adults and college students with all major decisions (Gray et al., 2021; Spurk \& Straub, 2020; Tomazek \& Muchacka-Cymerman, 2020); as such, we want to explore if the recent pandemic affects occupational planning, given student personality traits. How researchers have typically quantified attitudes with career planning has in fact been explored (Gray et al., 2020; Gray et al., 2021) — but factors affecting indecision, low self-efficacy (SE), and mental health- have not yet been carefully examined.

Some personality traits can predict occupational performance. Wilmot and collaborators (2019) con- 
ducted a meta-analysis and found that conscientiousness affects job performance. This shows its positive effects in $98 \%$ of samples, as a great influence across vocations. Gray et al. (2020) support how conscientiousness can predict conflict and indecision, with the correlation between conscientiousness and job planning being significant as well. The Big 5 personality traits have been used to predict professional performance, although how its five core dimensions-openness to experience, extraversion, conscientiousness, agreeableness, and neuroticism (OCEAN) - affect EI, CDSE, and indecision have not been fully examined. Research on this area will contribute to the literature on vocational behavior and personality in young adults.

Based on the above information we hypothesize that EI and personality traits (e.g., conscientiousness) affect employment decisions, and that CDSE mediates EI and career indecision. We investigated the degree to which indecision was related to pre-existing measures [the Big 5 personality inventory, the career student planning scale (CSPS), and the career decision self-efficacy shortform (CDSE-SF)] during COVID-19. Whereas previous research found personality and SE differences between EI and job indecision (Gray et al., 2020); this study includes personality and CDSE as covariates, while EI, CDSE, and career planning are predictive of more general decisions. Our mediation model assesses how procrastination influences indecision during a global pandemic.

\section{Methods}

\section{Participants and Procedures}

A total of 147 students was recruited from small, liberal arts colleges in southeast Arkansas and southern California. The experimenters ask them to answer all questionnaires, but thirteen participants failed to answer 5 or 6 questions, so were excluded ( $N=134 ; 104$ females and 30 males). All study procedures that involved human participants were performed in accordance with APA's ethical standards and the $1975 \mathrm{Hel}-$ sinki Declaration. Each participant voluntarily participated in the study, and informed consent was obtained so that debriefing could take place after its completion. The distribution of self-identified race was $65 \%$ White, $27 \%$ Black/African-American, $1 \%$ Native American, and the rest indicated 'other.' All participants were fulltime students at four-year universities $(M=22.28, S D=6.05)$ and recruited via email, with digital surveys administered after the pandemic lockdown. Students received extra credit for participation.

\section{Measures}

\section{Career Student Planning Scale (CSPS)}

Gray et al. (2021) created a new 8-item, unidimensional scale as a reliable measure of career planning. The CSPS uses a 5-point Likert-type scale All negatively worded items were scored in reverse, showing the coefficient alpha to be .86 (Table 3 ).

\section{Big 5 Personality Inventory (BFI)}

We used John and Srivastava's (1999) BFI, based on Goldberg's model of personality. The 45-item measure is comprised of OCEAN: (a) openness, (b) conscientiousness, (c) extroversion, (d) agreeableness, and (e) neuroticism. BFI uses a 5 5-point Likert-type scale ranging from 1 (strongly disagree) to 5 (strongly agree). The coefficient alphas of this study were (a) .60, (b) .77, (c) .72 , and (e) .76 .

\section{Career Decision Self-efficacy Short-form (CDSE-SF)}

Taylor and Betz (1983) CDSE-SF measure was used in this study. The 25-items form includes career SE and self-reported frequency on a 5-point Likert-type scale ranging from 1 (no confidence) to 5 (complete confidence). Our calculated Cronbach's alpha was 95 .

\section{Career Decision Difficulty Questionnaire (CDDQ)}

The CDDQ measure was used to access participant indecision. Created in 1996 by Gati, Krausz, and Osipow, it consists of the following subscales: (a) lack of readiness (CDDQ-R: lack of motivation, general indecisiveness, and dysfunctional beliefs), (b) lack of information (CDDQ-L: the stage of one's decision making, occupation, and the need for additional information), and (c) difficulties related to inconsistent information (CDDQ-D: unreliable information, and internal and external conflicts). This 34-item measure encourages participants to rate the extent to which each statement illustrates their professional decisions on a 9-point Likert-type scale, ranging from 1 (does not describe me) to 9 (describes me well). Fabio, Palazzeschi, Levin, and Gati (2015) found high internal consistency: (a) .89 for lack of readiness, (b) .90 for lack of information, and (c) .92 for inconsistent information. Cronbach's alpha for the scale in this study was 0.94 . 


\section{Wong and Law's Emotional Intelligence Scale (WLEIS)}

Wong and Law's EI scale (2002) assessed participant suitability for workplace situations. Participants were scored on 16 items (every four items was one factor, so a 4-factor structure emerged) on a 7-Likert-type scale from 1 (strongly disagree) to 7 (strongly agree). Wong and Law found internal consistency for four factors from .83 to .90 . Our Cronbach's alpha for WLEIS, including those four factors, was .91.

\section{Data Analysis Plan}

Two study analyses (Studies 1 and 2) were done. For Study 1 we conducted three multiple regressions to observe the effects of the Big 5 personality traits on each dependent variable - CDSE, CSPS, and CDDQ. For CDDQ, the Big 5 effect on certain traits was examined at subscale levels. We conducted three additional multiple regressions on the CDDQ subscales to examine the impact of Big 5 personality traits in terms of college student indecision. Study 2 examined the mediating effect of CDSE on EI and CDDQ. This model was able to test whether CDSE actually mediates EI while predicting CDDQ.

\section{Results}

The sample size was naturally obtained; we tried to recruit as many participants as possible for a larger sample, but due to the pandemic, a total of 134 was obtained. We used power analysis based on our sample: by using G*POWER for simple regression, the power was .8. A sample of 134 is not a small sample, although a larger sample would have been more desirable.

\section{Study 1 Multiple Regression Analyses}

Big 5 traits were independent variables in the six-multiple regression analyses on employment traits (Table 1 and 2). When CDSE was predicted by personality measure, conscientiousness $(t=4.83, p$ $<.001)$ and openness $(\mathrm{t}=4.196, \mathrm{p}$ $<0.001)$ were significant, $\mathrm{F}(5,128)$ $=15.64, \mathrm{p}<.001, \mathrm{R}^{2}=.38$. Neurot$\operatorname{icism}(\mathrm{t}=-2.45, \mathrm{p}=0.016)$ was a strong predictor of personality, $\mathrm{F}(5$, $128)=3.94, \mathrm{p}<.01, \mathrm{R}^{2}=.13$ when CSPS was regressed by that measure.
Neuroticism $(\mathrm{t}=4.39, \mathrm{p}<.001)$ was the only significant predictor, $\mathrm{F}(5$, $128)=5.58, \mathrm{p}<.01, \mathrm{R}^{2}=.18$ when we performed the multiple regression analysis of CDDQ and the Big 5 measure. These variables show statistical significance when predicting readiness (CDDQ-R), lack of information (CDDQ-L), and difficulties with inconsistent information (CDDQ-D). Neuroticism $(t=6.08, p<.001)$ was the only predictor of CDDQ-R, $\mathrm{F}$ $(5,128)=7.96, \mathrm{p}<.001, \mathrm{R}^{2}=.24$. In multiple regressions of three sub scales of CDDQ in predicting CDDQ-L, neuroticism was the significant personality trait $(\mathrm{t}=3.8, \mathrm{p}<.001), \mathrm{F}$ $(5,128)=4.72, \mathrm{p}<.001, \mathrm{R}^{2}=.16$. When predicting CDDQ-L, neuroticism $(t=2.3, p=.022)$ was the most significant personality trait, $\mathrm{F}(5,128)$ $=2.63, \mathrm{p}=.027, \mathrm{R}^{2}=.16$.

\section{Study 2}

\section{Mediation Model}

Results of the mediation model for EI, CDSE, and CDDQ show that the positive affect of CDSE mediated between EI and CDDQ (Figure 1). The effect of EI on CDDQ was mediated via CDSE. The regression coefficient for EI and CDDQ as

Table 1

Summary of Regression Analysis for Big 5 Personality Predicting Career Factors $(N=134)$

\begin{tabular}{|c|c|c|c|c|c|c|c|c|c|c|c|c|c|c|c|}
\hline \multirow{2}{*}{ Variables } & \multicolumn{5}{|c|}{ Study 1.1 (CDSE) } & \multicolumn{5}{|c|}{ Study 1.2 (CSPS) } & \multicolumn{5}{|c|}{ Study 1.3 (CDDQ) } \\
\hline & $\mathrm{B}$ & SE B & $\beta$ & $\mathrm{t}$ & $\mathrm{p}$ & $\mathrm{B}$ & SE B & $\beta$ & $\mathrm{t}$ & $\mathrm{p}$ & $\mathrm{B}$ & SE B & $\beta$ & $\mathrm{t}$ & $\mathrm{p}$ \\
\hline EXTRA & 0.255 & 0.234 & 0.086 & 1.090 & 0.278 & 0.072 & 0.085 & 0.079 & 0.844 & 0.400 & 0.003 & 0.022 & 0.011 & 0.126 & 0.900 \\
\hline AGREE & 0.309 & 0.266 & 0.089 & 1.162 & 0.247 & 0.104 & 0.097 & 0.097 & 1.078 & 0.283 & -0.008 & 0.025 & -0.027 & -0.306 & 0.760 \\
\hline CONSC & 1.557 & 0.323 & 0.386 & 4.828 & $<0.001$ & 0.165 & 0.117 & 0.133 & 1.405 & 0.162 & -0.038 & 0.031 & -0.114 & -1.236 & 0.219 \\
\hline NEURO & -0.068 & 0.232 & -0.022 & -0.292 & 0.771 & -0.206 & 0.084 & -0.220 & -2.446 & 0.016 & 0.097 & 0.022 & 0.384 & 4.387 & $<0.001$ \\
\hline OPENN & 1.117 & 0.266 & 0.301 & 4.196 & $<0.001$ & -0.042 & 0.097 & -0.037 & -0.436 & 0.664 & 0.034 & 0.025 & 0.111 & 1.348 & 0.180 \\
\hline
\end{tabular}


Table 2

Summary of Regression Analysis for Big 5 Personality Predicting Sub-scales of Career Indecision $(N=134)$

\begin{tabular}{|c|c|c|c|c|c|c|c|c|c|c|c|c|c|c|c|}
\hline \multirow{2}{*}{ Variables } & \multicolumn{5}{|c|}{ Study 1.3.1 (CDDQ_R) } & \multicolumn{5}{|c|}{ Study 1.3.2 (CDDQ_L) } & \multicolumn{5}{|c|}{ Study 1.3.3 (CDDQ_D) } \\
\hline & $\mathrm{B}$ & SE B & $\beta$ & $\mathrm{t}$ & $\mathrm{p}$ & $\mathrm{B}$ & SE B & $\beta$ & $\mathrm{t}$ & $\mathrm{p}$ & $\mathrm{B}$ & SE B & $\beta$ & $\mathrm{t}$ & $\mathrm{p}$ \\
\hline EXTRA & 0.010 & 0.017 & 0.049 & 0.561 & 0.576 & -0.004 & 0.030 & -0.011 & -0.120 & 0.904 & 0.005 & 0.030 & 0.015 & 0.153 & 0.879 \\
\hline AGREE & 0.009 & 0.020 & 0.040 & 0.473 & 0.637 & -0.003 & 0.034 & -0.007 & -0.078 & 0.938 & -0.031 & 0.034 & -0.086 & -0.928 & 0.355 \\
\hline CONSC & 0.013 & 0.024 & 0.050 & 0.566 & 0.572 & -0.066 & 0.041 & -0.147 & -1.581 & 0.116 & -0.053 & 0.041 & -0.124 & -1.281 & 0.203 \\
\hline NEURO & 0.104 & 0.017 & 0.513 & 6.084 & $<0.001$ & 0.113 & 0.030 & 0.337 & 3.797 & $<0.001$ & 0.069 & 0.030 & 0.214 & 2.322 & 0.022 \\
\hline OPENN & 0.025 & 0.020 & 0.103 & 1.295 & 0.198 & 0.030 & 0.034 & 0.074 & 0.889 & 0.376 & 0.048 & 0.034 & 0.123 & 1.417 & 0.159 \\
\hline
\end{tabular}

Table 3

Career Student Planning Scale (CSPS) Questionnaires and item-total correlation after reverse coding (N=134)

\begin{tabular}{|c|c|c|c|}
\hline Item & Questionnaires & Reverse coding & Item-total correlation \\
\hline 1 & I have chosen a major. & & 0.58 \\
\hline 2 & It was/is difficult to choose a major. & Y & 0.46 \\
\hline 3 & I plan to stick with my major. & & 0.61 \\
\hline 4 & I am satisfied with my major. & & 0.60 \\
\hline 5 & I know what I want to do in life. & & 0.80 \\
\hline 6 & I know what I am going to do after college. & & 0.73 \\
\hline 7 & I have chosen a career to pursue after college. & & 0.76 \\
\hline 8 & It was/is difficult to choose a career path. & Y & 0.34 \\
\hline
\end{tabular}

well as for CDSE and CDDQ were significant. The indirect effect was $(.70) *(-.03)=-0.02$, so we tested significance by using bootstrapping procedures. Unstandardized indirect effects were computed for 1,000 bootstrapped samples, and a 90\% CI was computed with indirect effects at the $2.5^{\text {th }}$ and $97.5^{\text {th }}$ percentiles. The bootstrapped unstandardized effect was -.02 , as the $95 \%$ CI ranged from - .03 to .01 . The indirect effect was statistically significant at $\mathrm{p}<.01$.

\section{Discussion}

This study explored how Big 5 personality traits, EI, CSPS, and CDSE-SF, are related to career indecision (CDDQ). Findings suggest that EI is negatively correlated to career indecision, which substantiates the work of Gray et al. (2020) as well as previous research (Gottlieb \& Gøtzsche-Astrup, 2020; Wilmot, Wanberg, Kammeyer-Mueller, \& Ones, 2019). Personality traits like conscientiousness and neuroticism are related to CDSE, CSPS, and CDDQ. We examined variables that influenced occupational indecision as most students experience mental health concerns when facing challenges. The first step involves related research, so this could result in an evidence-based study. Two specific goals of our research were: a) to examine the relationship between EI and $\mathrm{CDDQ}$, and $\mathrm{b}$ ) the mediating role of CDSE. The COVID-19 pandemic lockdown creates momentum among college students, who are nearly in 
Figure 1

Mediation Model Among the Given Variables

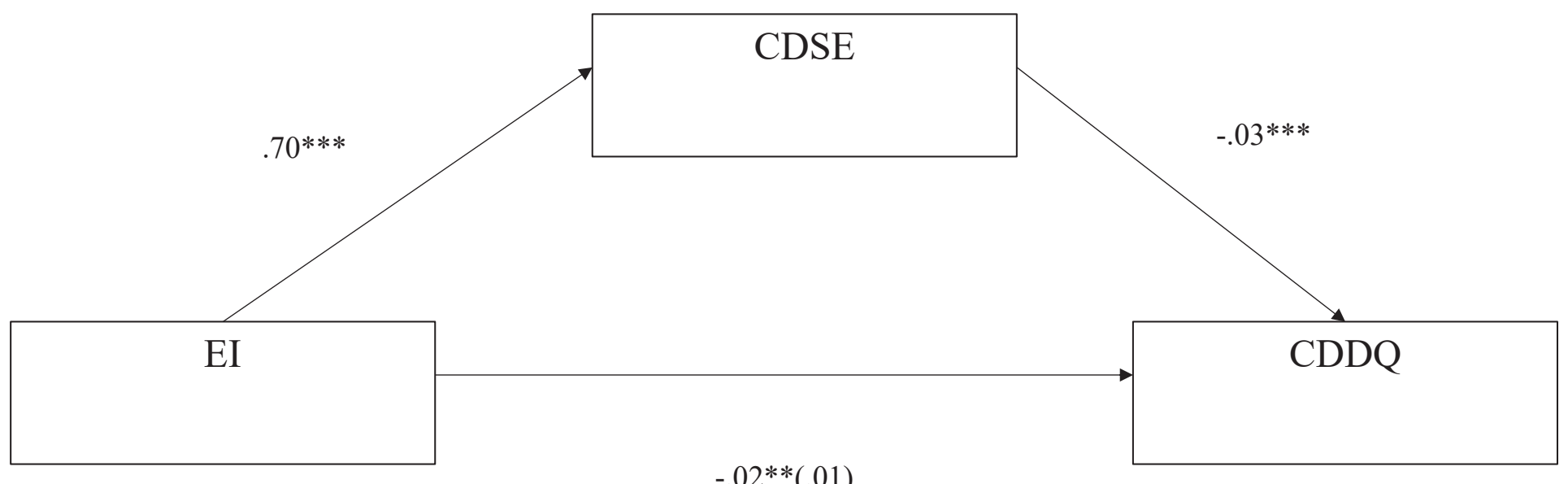

the job market. This study extends personality theories by including the COVID-19 pandemic, along with career decisions, and the mediating role of CDSE for EI and CDDQ

Findings suggest that EI is positively related to future work behavior and that CDSE mediates the relationship between them, which previous studies also support (Chung, 2002; Coetzee \& Harry, 2014; Fabio, Palazzechi, Levin, \& Gati, 2015; Falco \& Summers, 2019; Gati, Krausz, \& Osipow, 1996; Gray, Lee, \& Kim, 2020; Jiang 2016; Law, Wang, \&

Song, 2004). These variables have a strong impact on employment decisions. We compared how EI, individual SE, and personality traits were contributing factors in assessing work behavior and found that CDSE mediates between EI and career indecision.

\section{Limitations and Future Research Directions}

This study relied on self-reported measures, so direct causality of variables may not have been fully addressed, while shared method variance could have affected it. Our sam- ple size was relatively small, with the use of convenience sampling, so the findings are not highly generalizable. Self-report questionnaires may not exclude the possibility that participant responses could be affected by social desirability factors. Longitudinal or mixed method designs, comprised of larger and more diverse samples, would increase generalizability. However, the design allowed us to account for confounding variables. As stated, the research was conducted to examined personality traits, EI, and other variables related to professional conflict and indecision.

We aimed to determine the factors with the greatest influence on career indecision - as most college students are conflicted by low SE and individual personality traits. The first step involves related research so that this results in an evidence-based study: this will likely extend personality theories by examining how closely related variables might be integrated into a mediation model (Han, Kim, \& Kim, 2017).

This work is narrowly focused on potential contributing factors that could affect young adults. Despite its limitations, we attempted to offer a greater understanding of the direct and indirect relationship between EI and CDDQ, when CDSE was the mediator. Our findings may inform academic counselors and educational professionals, who comprehend the predictors of career decisions in college students, and who could use this information for strategies that reinforce behaviors associated with positive personality traits. As such, we will expand the research with existing studies - which could be used for future research by including other experiments, measures, and participants.

\section{References}

Ahorsu, D. K., Lin, C-Y., Imani, V., Saffari, M. Griffiths, M. D., Pakpour, A. H. (2020). The fear of COVID-19 scale: Development and initial validation. International Journal of Mental Health and Addiction, 1-9. https://doi. org/10.1007/s11469-020-002708

Campagna, C. G., \& Curtis, G. J. (2007). So worried I don't know what to be: Anxiety is associated with increased career indecision 
and reduced career certainty. Australian Journal of Guidance and Counselling, 17(1), 91-96. https://doi.org/10.1375/ ajgc.17.1.91

Chung, Y. B. (2002). Career decision-making self-efficacy and career commitment: Gender and ethnic differences among college students. Journal of Career Development, 28, 277 284. https://doi.org/10.117 7/089484530202800404

Coetzee, M., \& Harry, N. (2014). Emotional intelligence as a predictor of employees' career adaptability. Journal of Vocational Behavior, 84, 9097. https://doi.org/10.1016/j. jvb.2013.09.001

Cortina, J. M. (1993). What is coefficient alpha? An examination of theory and applications. Journal of Applied Psychology, 78(1), 98-104. https://doi. org/10.1037/0021-9010.78.1.98

Fabio, A. D., Palazzeschi, L., Levin, N., \& Gati, I. (2015). The role of personality in the career decision-making difficulties of Italian young adults. Journal of Career Assessment, 23(2), 281-293. https://doi. org/10.1177/1069072714535031.

Falco, L. D., \& Summer, J. J. (2019). Comparing ability and self-report trait emotional intelligence, fluid intelligence, and personality traits in career decision. Personality and Individual Differences, 64, 174-178. https://doi. org/10.1177/0894845317721651

Gati, I., Krausz, M., \& Osipow, S. H. (1996). A taxonomy of difficulties in career decision making. Journal of Counseling Psychology, 43(4), 510-526. https://doi. org/10.1037/0022-0167.43.4.510

Gottlieb, T., \& Gøtzsche-Astrup, O. (2020). Personality and work-re- lated outcomes through the prism of socioanalytic theory: A review of meta-analyses. Nordic Psychology. Advance online publication. https://doi.org/10.10 80/19012276.2020.1756902

Gray, M. A., Kim, M., \& Lee, S. (2021). Simplifying the measurement of college students' career planning: the development of career student planning scale during the COVID-19 pandemic. Experimental Results, 2, e4, 1-9. https://doi.org/10.1017/ exp. 2020.69

Gray, M. A., Lee, S., \& Kim, M. (2020). Comparing self-reported emotional intelligence, self- efficacy, and personality traits in college students' career decision-making: A pilot study. In S. Lee (Ed.), Exploring the opportunities and challenges of college students (pp. 205-217). NOVA Science Publishers, Inc. Hair, J. F., Jr., Black, W. C., Babin, B. J., \& Anderson, R. E. (2019). Multivariate data analysis $\left(8^{\text {th }}\right.$ ed.). Cengage Learning, EMEA. Han, S., Kim, K, \& Kim, J. (2017). Understanding nomophobia: Structural equation modeling and semantic network analysis of smartphone separation anxiety. Cyberpsychology, Behavior, and Social Networking, 20(7), 419-427. https://doi.org/10.1089. cyber.2017.0113

Işik, E. (2012). The relationship of career decision self-efficacy, trait anxiety, and affectivity among undergraduate students. Psychological Reports: Human Resources \& Marketing, 111(3), 805-813. https:// doi.org/10.2466/01.09.10. PR0.111.6.805-813

Jiang, Z. (2016). Emotional intelligence and career decision-making self-efficacy: Mediating roles of goal commitment and professional commitment. Journal of Employment Counseling, 53(1), 30-47. https://doi. org/10.1002/joec. 12026

John, O. P., \& Srivastava, S. (1999). The Big-Five trait taxonomy: History, measurement, and theoretical perspectives. In L. A. Pervin \& O. P. John (Eds.), Handbook of personality: theory and research (Vol. 2, pp. 102-138). New York: Guilford Press.

Law, K. S., Wang, C. S., \& Song, L. J. (2004). The construct and criterion validity of emotional intelligence and its potential utilities for management studies. Journal of Applied Psychology, 89(3), 483-496. https://doi. org/10.1037/0021-9010.89.3.483

MacCann, C., Jiang, Y., Brown, L. E. R., Double, K. S., Bucich, M., \& Minbashian A. (2020). Emotional intelligence predicts academic performance: A meta-analysis. Psychological Bulletin, 146(2), 150-186. http://dx.doi. org/10.1037/bul0000219

Mahmud, M. S., Talukder, M. U., Rahman, S. M. (2020). Does 'fear of COVID-19' trigger career anxiety? An empirical investigation considering depression from COVID-19 as a mediator. Journal of Social Psychiatry, 67, 1-11. https://doi. org/10.1177.0020764020935488

Mojgan, F. N., Kadir, R. A., \& Soheil, S. (2011). The relationship between state and trait anxiety with career indecision of undergraduate students. International Education Studies, 4(3), 31-35. https://doi.org/10.5539/ies. v4n3p31

Spurk, D., \& Straub, C. (2020). Flexible employment relationships and careers in times of the COVID-19 pandemic. 
Journal of Vocational Behavior, 119, e103435. https://doi. org/10.1016/j.jvb.2020.103435

Taylor, K. M., \& Betz, N. E. (1983). Applications of self-efficacy theory to the understanding and treatment of career indecision. Journal of Vocational Behavior, 22(1), 63-81. https://doi.org/10.1016/00018791(83)90006-4

Tomaszek, K., Muchacka-Cymerman, A. (2020). Thinking about my existence during COVID-19, I feel anxiety and awe-The mediating role of existential anxiety and life satisfaction on the relationship between PTSD symptoms and post-traumatic growth. International Journal of Environmental Research and Public Health, 17(19), 7062. https://doi. org/10.3390.ijerph17197062

Wilmot, M. P., Wanberg, C. R., Kammeyer-Mueller, J. D., \& Ones, D. S. (2019). Extraversion advantages at work: A quantitative review and synthesis of the meta-analytic evidence. Journal of Applied Psychology, 104(12), 1447-1470. https://doi. org/10.1037/ap10000415

Wong, C. S., \& Law, K. S. (2002). Wong and Law emotional intelligence scale (WLEIS). [Database record]. APA Psyc Tests. https:// doi.org/10.1037/t0798-000 